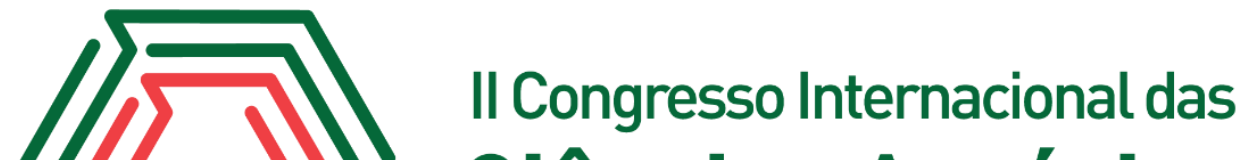 Ciências Agrárias COINTER - PDVAgro 2017
}

\section{INFLUÊNCIA DA SALINIDADE NO PERFIL SENSORIAL DA TILÁPIA (Oreochromis niloticus)}

\author{
Apresentação: Pôster
}

\begin{abstract}
Lucas de Oliveira Soares Rebouças ${ }^{1}$; Julianna Paula do Vale Figueiredo ${ }^{2}$; Ana Cecília Nunes de Mesquita ${ }^{3}$; Josué dos Santos Júnior ${ }^{3}$; Patrícia de Oliveira Lima ${ }^{4}$
\end{abstract}

\section{Introdução}

No Brasil, especificamente na região Nordeste o cultivo da Tilápia está sendo uma alternativa ao cultivo do camarão marinho. Devido ao surto da mancha branca que tem devastado grandes áreas de cultivo e abalando o setor (Rebouças et al., 2017).

Como a tilápia é considerada uma espécie rústica, tolerando grandes variações de salinidade, está sendo comum a ocupação de áreas destinadas à produção de camarão por cultivos de tilápia. A infraestrutura instalada para o cultivo do camarão pode ser também, utilizada em cultivos consorciados (policultivo de camarão e tilápia) ou mesmo em monocultivo de tilápias, com mínimas adaptações nos viveiros ou no manejo de cultivo (Kubitza, 2011; Candido et al., 2006).

Além disso, culturalmente existe uma maior preferência por peixes de água salgada. Isso se dá devido à presença de sabores (off flavor) descritos pelos consumidores como sabor de "terra" ou "mofo" comum nos peixes de água doce. No entanto, vários estudos mostram que a presença de off flavor do tipo "terra" e "mofo" está relacionado com a qualidade da água onde os peixes habitam (Miller et al., 1999; Persson, 1984).

Desta forma, o objetivo no presente estudo foi comparar as características sensoriais de tilápias cultivadas em ambientes de água doce e água salgada.

\footnotetext{
${ }^{1}$ Pós-Graduação em Ciência Animal, Universidade Federal Rural do Semiárido, lucaslosr@gmail.com

${ }^{2}$ Pós-Graduação em Ciência Animal, Universidade Federal Rural do Semiárido, juliannafigueiredo@hotmail.com

${ }^{3}$ Pós-Graduação em Ciência Animal, Universidade Federal Rural do Semiárido, cecilianmesquita@gmail.com

${ }^{4}$ Pós-Graduação em Ciência Animal, Universidade Federal Rural do Semiárido, josuejunior-07@hotmail.com

${ }^{4}$ Doutorado, Universidade Federal Rural do Semiárido, pattlima@ufersa.edu.br
} 


\section{Fundamentação Teórica}

Um dos principais parâmetros do cultivo relacionado ao sabor do pescado é a salinidade, onde espécies cultivadas em ambientes de água doce têm menos sabor característico de pescado do que as cultivadas em água salgada, devido à pressão osmótica ser menor nas espécies de água doce, existindo assim menores quantidades de componentes extratáveis de baixo peso molecular responsáveis pelo sabor, como os aminoácidos livres que são solúveis em água ou na saliva no momento da mastigação, influindo em um sabor mais intenso e característicos (Madrid, 2011).

Características específicas do ambiente de cultivo, além da salinidade, como temperatura e oxigênio dissolvido, promovem o surgimento de várias espécies de actinomicetos e cianobactérias sintetizadoras de 2-metilisoborneol (MIB) e geosmina (GEO), compostos que alteram negativamente o sabor e o odor de filés de peixes que passam a apresentar os sabores indesejáveis (Miller et al., 1999).

\section{Metodologia}

Para a pesquisa qualitativa, experimental, foram utilizadas 30 tilápias (O. niloticus) oriundas de dois cultivos comerciais distintos, sendo 15 denominados "AD”, os animais cultivados em água doce (salinidade 0 ppm) em sistemas de tanque-rede e 15 "AS" que correspondeu aos animais cultivados em água salgada (salinidade $30 \mathrm{ppm}$ ) em viveiros escavados de sistema consorciado com camarão, ambos da cidade de Apodi - RN. Os peixes utilizados no trabalho, em ambos os cultivos, possuíram o mesmo período de cultivo (6 meses) e a dieta fornecida foi a mesma, com ração comercial indicada para a espécie, comumente utilizada pelos produtores da região. Após a despesca, os peixes foram padronizados com peso aproximado de $1 \mathrm{~kg}$, abatidos através de choque térmico, acondicionados em caixas isotérmicas com gelo na proporção 1:1 (gelo/peixe) e transportados ao Laboratório de Análises Instrumentais e Sensoriais - LANIS, na Universidade Federal Rural do Semiárido - UFERSA, na cidade de Mossoró, RN, onde foi conduzido o experimento.

Para a análise sensorial, cada amostra foi padronizada em aproximadamente 20 gramas e codificada com três letras aleatórias (Meilgaard et al., 1999). Durante a análise, cada amostra de tilápia foi embalada em papel alumínio e em seguida passaram pelo processo de cocção em grill até atingir $75^{\circ} \mathrm{C}$ em seu interior. As amostras foram servidas em pratos descartáveis, acompanhadas de bolacha "água e sal” e água mineral. Participaram do teste 30 provadores treinados anteriormente ao teste, todos alunos de pós-graduação da UFERSA, de ambos os sexos, com idade variando entre 23 
a 49 anos. Os provadores avaliaram as 2 amostras servidas de forma aleatória, os quais foram orientados a limpar o paladar entre uma amostra e outra, para diminuir a interferência entre as análises. Foram analisados os aspectos qualitativos, como os atributos de sabor, odor, cor, textura e suculência e aceitação global. Para os registros dos julgamentos, foi utilizada uma escala hedônica estruturada de 9 pontos, onde para cada aspecto avaliado da ficha de avaliação era preenchida com notas de 1 a 9, sendo 1 referente ao desgostei muitíssimo e 9 ao gostei muitíssimo. Para analisar a preferência dos consumidores pelas amostras foi realizado um teste de comparação pareada.

Foi observado a normalidade e homocedasticidade dos dados das análises físicas e sensoriais, logo em seguida foram submetidos à análise de variância (ANOVA) e as médias foram comparadas pelo teste t ao nível de 5\% de significância, com o auxílio do programa SISVAR 5.6.

\section{Resultados e Discussões}

Os perfis sensoriais para as amostras analisadas, estão apresentados graficamente na Figura 1, mostrando que a tilápia cultivada em água salgada teve médias nos atributos sensoriais superiores a tilápia cultivada em água doce, embora tenha sido observada diferença significativa apenas no atributo cor.

$\mathrm{Na}$ análise sensorial, foi observada semelhança entre os atributos sensoriais de sabor, odor, textura e suculência. A tilápia cultivada em água salgada obteve maior nota comparada a tilápia de água doce. As médias dos atributos sensoriais estão descritos na Tabela 1.

Figura 1- Análise sensorial de tilápias (Oreochromis niloticus), provenientes do cultivo em água doce $(\mathrm{AD})$ e em água salgada (AS). Fonte: Própria

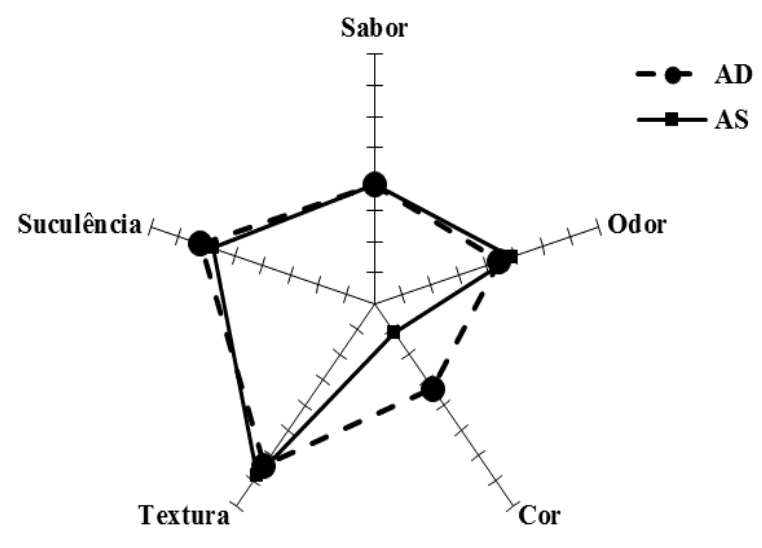


Segundo Biato (2005), tanto o pescado cultivado em água doce como o cultivado em água salgada, são muito suscetíveis à absorção de substâncias químicas presentes em seu ambiente, no entanto essa absorção é mais acentuada em pescado de água doce, pela sua maior permeabilidade através das brânquias. $\mathrm{O}$ autor ainda relata que substâncias provenientes das elevadas taxas de arraçoamento e decomposição algal (como a Geosmina) podem causar problemas de gosto e odor. $\mathrm{O}$ que não foi constatado no presente trabalho onde as amostras foram iguais estatisticamente no sabor e odor

Tabela 1. Médias dos descritores sensoriais de tilápias (Oreochromis niloticus), provenientes do cultivo em água doce (AD) e em água salgada (AS). Fonte: Própria

\begin{tabular}{lcc}
\hline Descritores Sensoriais & AD & AS \\
\hline Sabor & $4,82 \pm 2,29 \mathrm{a}$ & $4,82 \pm 2,38 \mathrm{a}$ \\
Odor & $5,46 \pm 2,65 \mathrm{a}$ & $5,90 \pm 2,60 \mathrm{a}$ \\
Cor & $4,36 \pm 2,09 \mathrm{a}$ & $2,15 \pm 1,65 \mathrm{~b}$ \\
Textura & $7,39 \pm 1,62 \mathrm{a}$ & $7,78 \pm 0,95 \mathrm{a}$ \\
Suculência & $7,21 \pm 1,87 \mathrm{a}$ & $6,78 \pm 2,14 \mathrm{a}$ \\
\hline
\end{tabular}

Valores seguidos de mesma letra nas linhas não diferem significativamente $(p>0,05)$ pelo teste $t$ de Student (média \pm SD, $n=30$ ).

\section{Conclusões}

A salinidade da água de cultivo não influenciou nos principais atributos sensoriais da tilápia, sendo detectada diferença pelos provadores apenas para o atributo cor. A tilápia de água salgada foi a preferida pelos provadores no teste de comparação pareada.

\section{Referências}

BIATO, D.O. Detecção e controle do off flavor em tilápia do Nilo (Oreochromis niloticus) por meio de depuração e defumação. 105 p. Dissertações de Mestrado. Escola Superior de Agricultura Luis de Queiroz. Piracicaba, 2005. 
CANDIDO, A.S.; DE MELO JÚNIOR, A.P.; DOS SANTOS, C.H.D.A.; DOS SANTOS COSTA, H.J.M.; IGARASHI, M.A. Policultivo do camarão marinho (Litopenaeus vannamei) com tilápia do Nilo (Oreochromis niloticus). Arquivos de Ciências Veterinárias e Zoologia da UNIPAR, v.9, p. 9-14, 2006.

KUBITZA, F.O. Cultivo de tilápia no Brasil: origens e cenário atual. status atual e as tendências da tilapicultura no Brasil. Revista Panorama da Aquicultura, Fortaleza, v.21, p.10-19, 2011.

MADRID, R.M. ¿Se puede modificar el sabor del pescado? Infopesca Internacional, v. 48, p. 1924, 2011.

MEILGAARD, G.; CIVILLE, V.; CARR, B.T. Sensory evaluation techniques. 2 Ed., CRC Press. Boca Ratón, 1991.

MILlER, D.; CONTE, E.D.; SHEN, C.Y.; PERSCHBACHER, P.W. Colorimetric approach to cyanobacterial oof-flavor detection. Water Science Technology, v. 40, p. 165-169, 1999.

REBOUÇAS, L. O. S., FIGUEIREDO, J. P. V., MESQUITA, A. C. N., JÚNIOR, J. S., ASSIS, A. P. P., CAMPÊLO, M. C. S., ... \& LIMA, P. O. Qualidade física e sensorial da tilápia (Oreochromis niloticus) cultivada em ambiente de água doce e salgada. Boletim de Indústria Animal, v.74, n.2, p. 116-121, 2017. 